\title{
Mechanical Integrity of Tissue Engineered Stented Transapical Heart Valves after Crimping Procedure
}

\author{
Magdalena Scheuer ${ }^{1 *}$, Trixi Hollweck ${ }^{1 *}$, René Bombien ${ }^{1}$, Rainer Kozlik-Feldmann ${ }^{2}$, Ulrike Haas ${ }^{1}$, Cornelia \\ Fano $^{3}$, Martin Dauner ${ }^{3}$, Jan-Marcel Hausherr ${ }^{4}$, Bruno Reichart ${ }^{1}$, Christoph Schmitz ${ }^{1}$ \& Bassil Akra ${ }^{1}$ \\ ${ }^{1}$ Department of Cardiac Surgery, Medical Center Munich University, Munich, Germany \\ ${ }^{2}$ Department of Paediatric Cardiology, Medical Center Munich University, Munich, Germany \\ ${ }^{3}$ Institute of Textile Technology and Process Engineering, Denkendorf, Germany \\ ${ }^{4}$ Fraunhofer Center for High-Temperature Materials and Design, Bayreuth, Germany \\ * Contributed equally to this study \\ Correspondence: Bassil Akra, Department of Cardiac Surgery, Medical Center Munich University, \\ Marchioninistrasse 15, 81377 Munich, Germany. Tel: 49-7095-6465. E-mail: \\ Bassil.Akra@med.uni-muenchen.de
}

Received: June 5, 2013 Accepted: August 20, 2013 Online Published: September 5, 2013

doi:10.5539/emr.v2n2p1 URL: http://dx.doi.org/10.5539/emr.v2n2p1

\begin{abstract}
Transapical heart valve implantation is a common minimally invasive procedure for valve replacement in high-risk patients. However, the use of synthetic prostheses for this procedure is limited due to reduced long-term durability. Tissue engineered stented heart valves are promising as prospective transcatheter heart valve prostheses. Therefore, the aim of this study was to determine the mechanical integrity of tissue engineered stented heart valves after crimping procedure. Stented non-degradable polyurethane heart valves (sPUHV) were successively seeded with fibroblasts and endothelial cells derived from human saphenous vein segments. Dynamic seeding procedure was performed by using a special 3D-rotating bioreactor. Colonized stented heart valves were exposed to mechanical loadings by crimping in a conventional heart valve crimper and were analyzed by micro-computerized tomography ( $\mu$-CT), scanning electron microscopy (SEM), immunohistochemistry (IHC) and immunocytochemistry (ICC). $\mu$-CT showed no damage of the sPUHV after crimping. A stable cellular coating with intact cell surfaces of crimped heart valves was demonstrated by SEM analysis. ICC and IHC observations also revealed the mechanical integrity of endothelial and fibroblast layers after crimping technique. It could be demonstrated that the crimping procedure does not affect the integrity of sPUHV structure and the cellular coating. This offers a potential use for tissue engineered stented heart valves for transapical heart valve replacement.
\end{abstract}

Keywords: heart valve, tissue-engineering, crimping, mechanical integrity, minimally invasive valve replacement

\section{Introduction}

The idea of minimally invasive heart valve implantation is more than 40 years old (Boretos, 1977; Moulopoulos, 1972). Meanwhile, transapical aortic valve implantation (TA-AVI) has evolved to a routine procedure in selected specialized centers providing a safe and reproducible treatment option for high-risk elderly patients suffering from severe symptomatic aortic stenosis (Kempfert et al., 2011). ElBardissi et al. described successful minimally invasive surgical approaches in reducing morbidity and improving survival after aortic valve replacement, especially in high risk patients (ElBardissi, Shekar, Couper, \& Cohn, 2011). However, concerns about valve crimping still arise. Crimping is required to be able to fit the valve in catheters for minimally invasive implantation. This valve preparation technique may decrease valve durability and shorten valve life-span (Bonhoeffer et al., 2002). Kiefer et al. (2011) used a subcutaneous rat model to evaluate whether crimping may affect long-term durability of biological valve prostheses. According to this study, transcatheter valve crimping did not necessarily affect leaflet calcification. However, the structural changes of the leaflets caused by crimping may have clinical significance. As a consequence different stent types and various scaffold materials were tested in the last decades, to find materials which can withstand the stress of preimplantation crimping (Hilbert, Ferrans, 
Tomita, Eidbo, \& Jones, 1987; Lo, Herold, \& Reul, 1988). At this point in time the durability of completely synthetic stented heart valves is still limited. Tissue engineered heart valves (TEHV) are an alternative which must be tested more stringently due to the fact that valve scaffolds are coated with cell layers which may be affected by crimping. Recently groups have investigated the impact of folding procedures on TEHV (Stock et al., 2006). Dijkman et al. (2012) showed adequate in-vivo functionality of TEHV after minimally invasive implantation in an ovine model, but a thickening of the leaflets was observed. The direct comparison of transapical and conventional surgical implantation techniques showed that crimping had no adverse effect on the integrity or functional outcome of TEHV. This suggests that a thickening of TEHV in vivo is neither caused by nor enhanced by the crimping procedure, but represents a functional tissue remodeling process. Moreover, Weber et al. (2012) already demonstrated the principal technical feasibility of a prenatal, transapical stent delivery as well as a fetal transapical implantation of a stented TEHV in an ovine model. These approaches demonstrate the first step towards possible future minimally invasive prenatal heart-valve-implantation procedures.

Against this background, minimally invasive implantation of heart valve substitutes becomes more important. For the treatment of high-risk patients over 75 years, this catheter-based heart valve replacement would be the method of choice to avoid a sternotomy and diverse associated complications. In addition, this treatment option would be preferred from young patients in particular from women for aesthetic reasons.

Therefore we aim to develop a cell-seeded aortic heart valve prosthesis based on a synthetic, non-degradable nonwoven. The geometry of the engineered prostheses should combine the beneficial characteristics of commercial heart valve substitutes concerning mechanical, rheological and hemodynamic properties, as well as biocompatibility. The high ductility of the nonwoven offers the potential for minimally invasive implantation. By testing our valves with a conventional synthetic heart valve crimper we replicated the preimplantation preparation of heart valves for transapical implantation more accurately. This was conducted to investigate if the valve preparation procedure for transapical valve replacement would affect the integrity of our cell-seeded heart valves.

\section{Materials and Methods}

In order to determine the mechanical integrity of tissue engineered stented heart valves after crimping procedure, stented non-degradable polyurethane heart valves (sPUHV) were initially seeded with human vascular cells. Therefore, vascular fibroblast (FB) and endothelial cells (EC) were obtained from human saphenous vein segments, expanded and phenotypic characterized by immunocytochemistry (ICC). The subsequent dynamic seeding procedure of sPUHV was performed by using a special 3D-rotating bioreactor to ensure a homogenous cell distribution on the scaffold. Colonized sPUHV were finally exposed to mechanical loadings by crimping in a conventional heart valve crimper. The mechanical integrity of sPUHV structure and cellular coating were visualized to develop quality control in tissue engineering using micro-computerized tomography $(\mu-\mathrm{CT})$, scanning electron microscopy (SEM), immunohistochemistry (IHC) and ICC.

\subsection{Isolation and Culture of Human Vascular Cells}

Remaining segments of saphenous veins explanted for use in coronary artery bypass grafting were collected as cell source and stored in M199 media at $4{ }^{\circ} \mathrm{C}$ for $1-5 \mathrm{~d}$ before processing. Samples were taken with the patients' informed consent and were allocated in an anonymous fashion with no indication of patient specific data. EC and FB were isolated as previously described (Fischlein et al., 1994; Haegerstrand, Gillis, \& Bengtsson, 1992). Briefly, for EC isolation, vein segments $(9.5 \pm 5.3 \mathrm{~cm})$ were cannulated and incubated with $0.8 \mathrm{mg} / \mathrm{ml}$ collagenase II (240 U/mg; Worthington, Lakewood, NJ, USA) in human serum albumin (Baxter Deutschland $\mathrm{GmbH}$, Unterschleißheim, Germany) for $30 \mathrm{~min}$ at $37^{\circ} \mathrm{C} / 5 \% \mathrm{CO}_{2}$. For $\mathrm{FB}$ isolation, cannulated vein segments were once more incubated with $2 \mathrm{mg} / \mathrm{ml}$ collagenase for $40 \mathrm{~min}$ at $37{ }^{\circ} \mathrm{C} / 5 \% \mathrm{CO}_{2}$. The obtained $\mathrm{EC}$ and $\mathrm{FB}$ were cultured in culture flasks $\left(12.5 \mathrm{~cm}^{2}\right.$, Becton Dickinson $\mathrm{GmbH}$, Heidelberg, Germany) in Endothelial Cell Growth Medium (Promocell GmbH, Heidelberg, Germany) supplemented with 6 \% FCS (Lonza GmbH, Köln, Germany) and $0.2 \%$ Penicillin/Streptomycin (Sigma Aldrich GmbH, Hamburg, Germany) and Fibroblast Growth Medium (Promocell GmbH, Heidelberg, Germany) supplemented with $11 \%$ FCS and $0.2 \%$ Penicillin/Streptomycin, respectively at $37{ }^{\circ} \mathrm{C} / 5 \% \mathrm{CO}_{2}$. Medium was exchanged every 2-3 days. Cells were passaged at confluency.

\subsection{Phenotypic Characterization of Vascular Cells}

EC and FB were phenotypic characterized by morphological observation using phase contrast microscopy (Carl Zeiss Mikrolmaging GmbH, Göttingen, Germany) and immunocytochemistry. EC were identified by their typical cobblestone appearance. FB were identified by observation of their characteristic elongated spindle-shape 
and multiple cellular extensions. For immunocytochemical verification of EC and FB cultures, the vascular cells were stained for CD31 (0.14 $\mu \mathrm{g} / \mathrm{ml}$; Dianova GmbH, Hamburg, Germany) and TE-7 (0.67 $\mu \mathrm{g} / \mathrm{ml}$, Millipore Corporation BioScience Division, Temecula, CA, USA), respectively according to manufacturer`s protocol using the HRP Detection System (Biozol GmbH, Eching, Germany). Briefly, cells were seeded on culture slides (BD Bioscience, Bedford, USA); at confluency, the cells were fixed and stored in $96 \%$ ethanol (Merck KGaA, Darmstadt, Germany) at $-80{ }^{\circ} \mathrm{C}$ for a minimum of $24 \mathrm{~h}$. The complete staining procedure was performed at room ambient conditions. Endogenous peroxidase activity in the vascular cells was blocked using $0.15 \% \mathrm{H}_{2} \mathrm{O}_{2}$ in $\mathrm{PBS}$ for $10 \mathrm{~min}$. After incubation with the primary antibody for $30 \mathrm{~min}$, cells were incubated with the biotinylated link for $10 \mathrm{~min}$. The cells were then incubated with HRP Streptavidin-label for $10 \mathrm{~min}$, followed by the AEC label (Vector Laboratories, Inc., Burlingame, CA, USA) for another $10 \mathrm{~min}$. Cell nuclei were stained with Mayer's hemalaun (Merck KGaA, Darmstadt, Germany; 1:4 in PBS). Controls for non-specific binding of biotinylated link were performed by excluding the primary antibodies. Stained cells were analyzed using bright field microscopy (Carl Zeiss Mikrolmaging GmbH, Göttingen, Germany).

\subsection{Fabrication of Heart Valves}

sPUHV (outer diameter $=20 \mathrm{~mm}$, inner diameter $=19 \mathrm{~mm}$, height $=25 \mathrm{~mm}$ ) for seeding of isolated $\mathrm{FB}$ and $\mathrm{EC}$ were produced by ITV Denkendorf (Denkendorf, Germany) using spraying technique. In order to generate heart valve tools for spraying, silicone models were prepared by using available heart valve metal models. These were initially covered with a protective film followed by a silicon application. After drying period, silicon models were released from metal models and filled with modelling cement. Cement models (figure 1a) were then modified in a dental practice in order to improve leaflet coaptation. After surface modification, new silicone models (figure 1b) were produced to cast optimized heart valve tools by using lead-tin alloy (figure 1c). For polyurethane (PU) valve production a polycarbonate-urethane solution was sprayed onto the proximal and distal ends of the valve tools at $0.8 \mathrm{ml} / \mathrm{min}$ and 3 bar (figure 1d). The randomly orientated PU fibres had a median diameter of $1.55 \mu \mathrm{m}$ (figure 1e). The valves were fixed to cobalt-chromium (CoCr, NP35N) stents (Figure 1f; diameter $=20 \mathrm{~mm}$; height $=25 \mathrm{~mm}$; Manemed Research \& Development, Bonn, Germany) using a conventional heart valve crimper (figure 1g; size 29, Edwards Lifesciences SAS, Unterschleißheim, Germany) and the aortas were sprayed at $0.8 \mathrm{ml} / \mathrm{min}$ at $3 \mathrm{bar}$ (figure $1 \mathrm{~h}$; spraying width $=100 \mathrm{~mm}$, feed rate $=100 \mathrm{~mm} / \mathrm{min}$, rod rotation $=500 \mathrm{rpm}$ ). sPUHV (figure 1i) were tempered overnight at $50{ }^{\circ} \mathrm{C}$ and were degassed in a high vacuum. Prior to seeding, sPUHV were $\gamma$-sterilized at $10 \mathrm{kGy}$ according to certified sterilisation procedure.

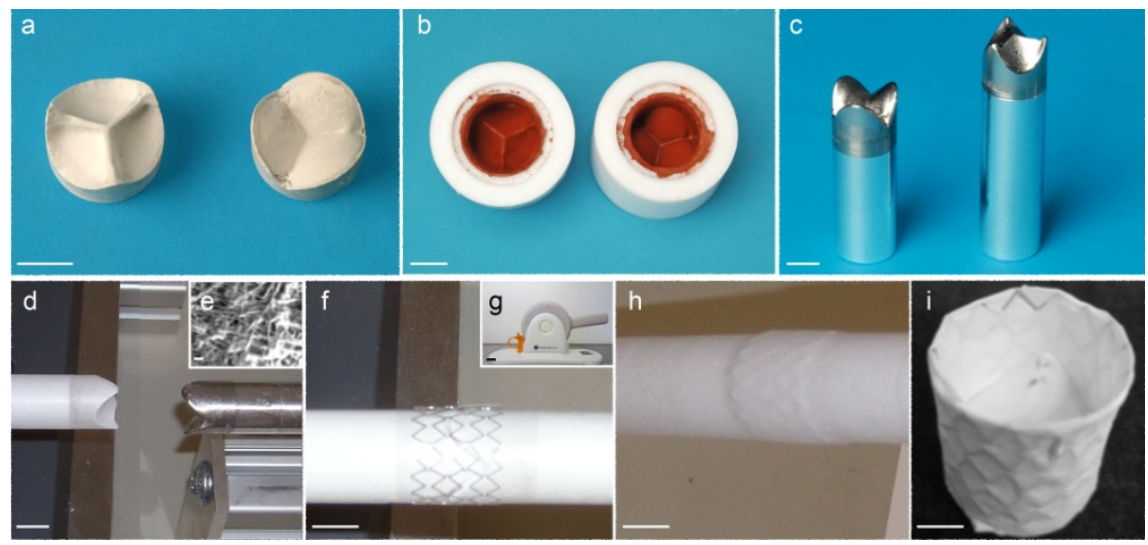

Figure 1. Fabrication of stented polyurethane heart valves (sPUHV)

Based on cement casts (a), silicone moulds (b) for lead casting of heart valve tools (c) were initially prepared. Polycarbonate-urethane solution was sprayed on the distal and proximal surfaces of the heart valve tools (d). Randomly orientated PU fibres had a median diameter of $1.55 \mu \mathrm{m}$ (e). Cobalt-chromium (CoCr, NP35N) stents (f) were applied by crimping, using a conventional heart valve crimper (g). After spraying a replicate of the aorta (h), sPUHV (i) were tempered overnight and degassed in a high vacuum. Scale bars: a, b, c, d, f, h = $10 \mathrm{~mm}$; e = $10 \mu \mathrm{m}, \mathrm{g}=20 \mathrm{~mm}, \mathrm{i}=5 \mathrm{~mm}$.

\subsection{Seeding Procedure}

sPUHV $\left(\mathrm{n}=5, \mathrm{~A}=37.7 \mathrm{~cm}^{2}\right)$ were fixed in a special Teflon ${ }^{\mathrm{TM}}$-bracket to avoid heart valve deformation and tissue damage during further processing. Moreover, this fixation unit simplifies the handling of the heart valve 
though reducing risk of contamination and enables a correct and easy positioning in the seeding system. Seeding procedure was performed as previously described (Gulbins et al., 2003). Briefly, heart valves were successively seeded with vascular FB $\left(1.5 \times 10^{6} / \mathrm{cm}^{2}\right)$ and EC $\left(1.5 \times 10^{6} / \mathrm{cm}^{2}\right)$. For each cell type, a dynamic seeding procedure was performed for $24 \mathrm{~h}$ using a 3D-rotating bioreactor (running interval: $2.5 \mathrm{~min}$; static interval: 30 min) followed by a static resting period of $6 \mathrm{~d}$ at $37{ }^{\circ} \mathrm{C} / 5 \% \mathrm{CO}_{2}$ to allow cell expansion and extracellular matrix formation. Partial medium exchanges were performed every 2-3 days.

\subsection{Crimping Procedure}

In order to simulate minimally invasive implantation procedure, cell-seeded SPUHV were positioned in a conventional heart valve crimper (figure 2a; Size 29, Edwards Lifesciences SAS, Unterschleißheim, Germany). A balloon catheter was longitudinally introduced (figure $2 \mathrm{~b}$ ) and sPUHV were crimped to a diameter of $10 \mathrm{~mm}$ (figure 2c). Crimped heart valves were kept in pre-warmed Endothelial Cell Growth Medium for 10 min at room temperature (RT) to imitate the duration of prosthesis positioning during implantation. Afterwards sPUHV were balloon-dilated (figure 2d).
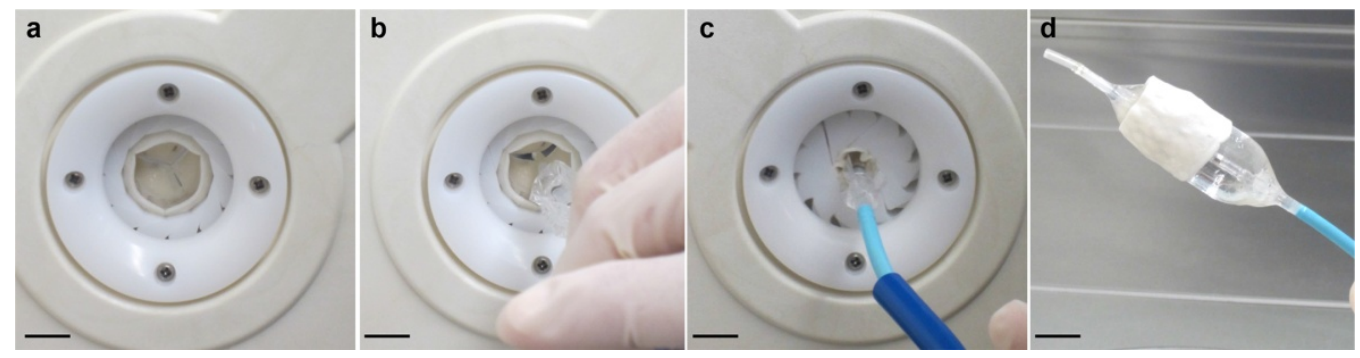

Figure 2. Crimping procedure

Seeded SPUHV were positioned in a heart valve crimper (a). After introducing a balloon-catheter (b), heart valves were crimped for $10 \mathrm{~min}$ (c). Crimped heart valves were balloon-dilated and prepared for analysis (d). Scale bars $=1 \mathrm{~cm}$.

\subsection{Micro-Computerized Tomography $(\mu-C T)$}

Scanning procedure and image generation were performed as previously described (Haller et al., 2013) for non-invasive analysis of sPUHV structure after crimping. Briefly, scans of sPUHV were performed on a dry scaffold at RT, after seeding the scaffold and finally after crimping and dilatation. $\mu$-CT analysis allowed a non-invasive analysis of several positions of the SPUHV. The tomographic investigations were performed using a $\mu$-CT machine of the type HR-150-03. The reconstructed complete volume of the heart valve consisted of $2048^{3}$ voxels with an edge length of $18 \mu \mathrm{m}$ and was reconstructed from 1600 individual X-ray radioscopy images. The detector used was a Perkin-Elmer flat panel detector type XRD 1621-CT3 consisting of $2048^{2}$ pixels. The X-ray source used a tungsten target with $1 \mathrm{~mm}$ copper shielding and was powered at $130 \mathrm{kV}$ with a current of $300 \mu \mathrm{A}$, generating a polychromatic X-ray spectrum. The total exposure time was $90 \mathrm{~min}$. The reconstruction of cross-sections was performed using a reconstruction algorithm developed by the Fraunhofer Institute EZRT, Fürth, Germany. Structural analysis and three-dimensional visualization were carried out using the visualization software VG-Studio Max, version 2.1 with an adapted wall-thickness algorithm developed by the University of Bayreuth.

Supravalvular, valvular and subvalvular samples as well as cusps samples were taken from the construct and analyzed using further microscopic methods.

\subsection{Scanning Electron Microscopy (SEM)}

SEM samples were prepared as to investigate the integrity of the cell coating on the valve construct post crimping. Samples from sPUHV were fixed in $456 \mathrm{ml}$ aqua bidest (Ampuwa, Fresenius Kabi Deutschland $\mathrm{GmbH}$, Bad Homburg v.d. H., Germany) supplemented with $0.75 \mathrm{ml} 1 \mathrm{~N}$ hydrochloric acid (Titrisol, Merck KGaA, Darmstadt, Germany), $43.5 \mathrm{ml}$ glutaraldehyd (Sigma-Aldrich Chemie GmbH, Steinheim, Germany) and $5.65 \mathrm{~g}$ sodium cocodylate trihydrate (Sigma-Aldrich Chemie $\mathrm{GmbH}$, Steinheim, Germany) at $4{ }^{\circ} \mathrm{C}$ for $48 \mathrm{~h}$. The fixed specimens were dehydrated in an ascending ethanol series $(30 \%, 50 \%, 70 \%$ and $96 \% \mathrm{EtOH})$ and then placed in $100 \%$ acetone (Merck KGaA, Darmstadt, Germany). After critical point drying the samples were sputtered with gold for $180 \mathrm{~s}$ at $10^{-5} \mathrm{mbar}$ and analyzed using a scanning electron microscope (SEM; Carl Zeiss Mikrolmaging GmBH, Göttingen, Germany). 


\subsection{Immunocytochemistry (ICC)}

The level of confluence of the endothelial cell layer after crimping was examined by intracellular staining of von Willebrand factor (vWF). Cell nuclei were visualized with a diamidinophenylindole (DAPI) nuclear counterstain. Samples of the seeded heart valves were fixed and permeabilized in methanol-acetone (1:1, Merck KGaA, Darmstadt, Germany) for 2 min at RT. After rinsing with phosphate buffered saline (PBS, Biochrom AG, Berlin, Germany) samples were incubated with the primary antibody (polyclonal rabbit anti human $\mathrm{vWF}, 40 \mu \mathrm{g} / \mathrm{ml}$, Sigma-Aldrich GmbH, Hamburg, Germany) diluted in PBS/10 \% FCS, for 45 min at $37{ }^{\circ} \mathrm{C}$. The samples were washed with PBS and incubated with the secondary antibody (goat anti rabbit IgG, Fluoresceinisothiocyanat (FITC) conjugate, $22 \mu \mathrm{g} / \mathrm{ml}$; Sigma-Aldrich $\mathrm{GmbH}$, Hamburg, Germany) for $30 \mathrm{~min}$ at $37^{\circ} \mathrm{C}$. The samples were washed with PBS and cell nuclei were stained with $1 \mu \mathrm{g} / \mathrm{ml}$ DAPI (Roche GmbH, Mannheim, Germany) diluted in PBS, for $20 \mathrm{~min}$ at RT. Samples from seeded heart valves which did not undergo mechanical strain procedures served as positive controls. Negative controls for non-specific binding of the secondary antibody were performed by exclusion of the primary antibody. For fluorescence microscopy, samples were immersed in a small volume of PBS; fluorescence signals were detected using a computer-guided fluorescence microscope (Carl Zeiss Mikrolmaging GmBH, Göttingen, Germany). The excitation and emission of the secondary antibody conjugated FITC was $495 \mathrm{~nm}$ and $517 \mathrm{~nm}$, respectively. Fluorescence measurements of samples and negative controls were taken at identical exposure times.

\subsection{Immunohistochemistry (IHC)}

Immunhistochemical staining was performed to differentiate between FB and EC layers on the SPUHV after the crimping procedure. Samples were fixed in $4 \%$ formaldehyde (Microcos GmbH, Garching, Germany) for $10 \mathrm{~d}$ at $4{ }^{\circ} \mathrm{C}$ and the stents were carefully removed. Paraffin-embedded specimens were sectioned at $10 \mu \mathrm{m}$ and were stained for CD31 (0.09 $\mu \mathrm{g} / \mathrm{ml}$; Dianova GmbH, Hamburg, Germany) and TE-7 (2 $\mu \mathrm{g} / \mathrm{ml}$, Millipore Corporation BioScience Division, Temecula, CA, USA) using the HRP Detection System (Biozol GmbH, Eching, Germany) according to manufacturer's protocol. Briefly, endogenous peroxidase activity was blocked using $0.12 \% \mathrm{H}_{2} \mathrm{O}_{2}$ in PBS for $10 \mathrm{~min}$. After incubation with the primary antibody overnight at $4{ }^{\circ} \mathrm{C}$ the samples were incubated with the biotinylated link for $10 \mathrm{~min}$. The cells were then incubated with HRP Streptavidin-label for $10 \mathrm{~min}$, followed by AEC labeling (Vector Laboratories, Inc., Burlingame, CA, USA) for another $10 \mathrm{~min}$. Cell nuclei were stained with Mayer's hemalaun (Merck KGaA, Darmstadt, Germany; 1:4 in PBS). Negative controls for non-specific binding of the biotinylated link were performed by exclusion of the primary antibody. Sections were analyzed using bright field microscopy (Carl Zeiss Mikrolmaging GmBH, Göttingen, Germany).

\section{Results}

\section{1 sPUHV Structure Was Not Affected after Crimping Procedure}

A non-invasive analysis of sPUHV was performed by $\mu$-CT. Figure 3 shows three-dimensional graphics of the whole sPUHV in native (a), seeded (b) and dilated state (c). sPUHV revealed an intact surface in all states.
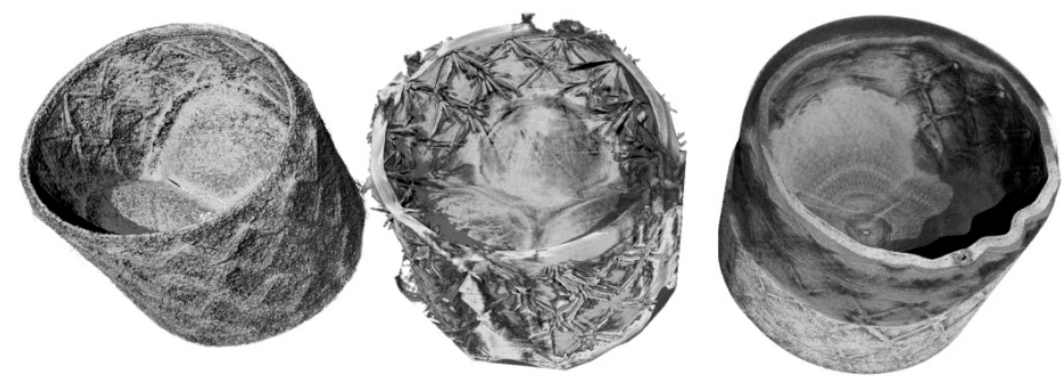

Figure 3. $\mu-\mathrm{CT}$ analysis of sPUHV structure

Three-dimensional graphics of the sPUHV in native (a), seeded (b) and dilated (c) states demonstrated the mechanical integrity of the sPUHV structure after crimping. Scale bars $=35 \mathrm{~mm}$.

\section{2 sPUHV Were Homogenously Colonized after Crimping Procedure}

Seeding and crimping of sPUHV was performed as described in the experimental procedure. Topography of crimped SPUHV was analysed by SEM. The subvalvular region of the inner vessel wall replicate showed a confluent cell surface with no visible damage. Moreover, typical cobblestone morphology was observed even 
after the crimping procedure, indicating an intact endothelial cell layer (figure 4a). As demonstrated in figures 4b-d, valvular, supravalvular and leaflet specimens revealed a confluent cellular coating with marginal damage to the cell layers. Further results indicate that cell layers on the outer vessel wall can withstand the mechanical stress of crimping better than those on the inner vessel wall (data not shown).

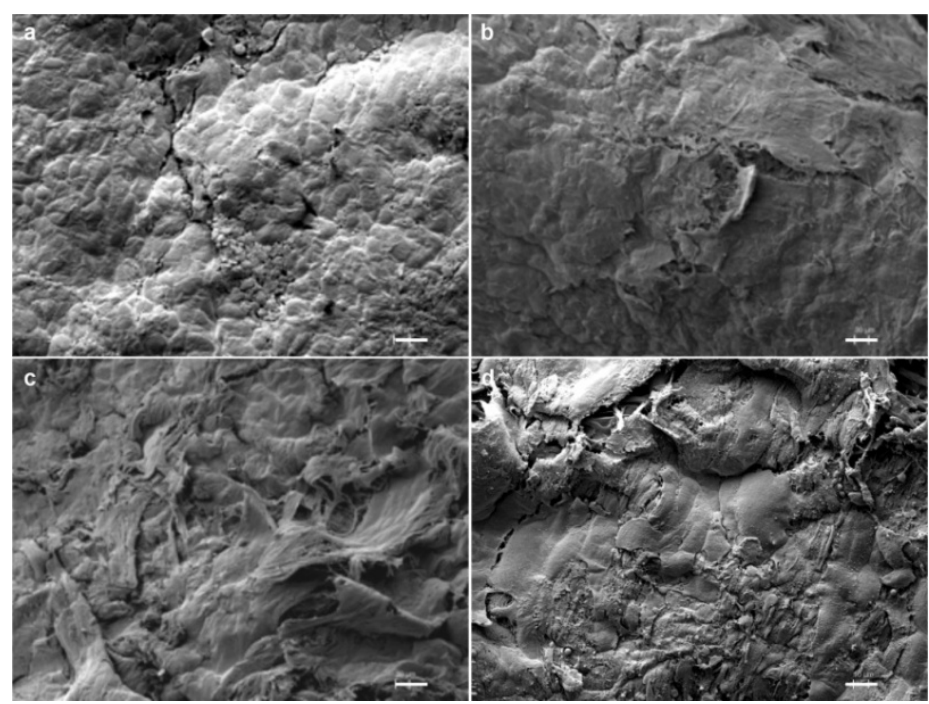

Figure 4. SEM analysis of cell-seeded sPUHV after crimping procedure

Subvalvular samples of inner vessel wall showed a confluent cell distribution with cobblestone morphology indicating successful endothelialization (a). The valvular (b) and supravalvular (c) regions as well as the leaflets (d) exhibit a confluent cell layer with minor cell damage. These representative images of five independent experiments each performed with cells from a different donor. Scale bars $=50 \mu \mathrm{m}$.

\section{3 sPUHV Were Endothelialised after Crimping Procedure}

Immunohistochemical analysis was carried out to detect fibroblast and endothelial layers after performing the crimping procedure. TE-7, a fibroblast marker, and CD31, an endothelial cell marker, were stained for. Cell nuclei were counterstained with hemalaun. In figures 5a-d cell nuclei (purple) of a continuous fibroblast multilayer (brown; arrows) found on the internal and external surfaces of the supravalvular (a), leaflet (b), valvular (c) and subvalvular (d) regions is shown. Additionally, these regions revealed an endothelial lining (figure 5e-h, brown; arrows) with minimal disruptions after mechanical stress. Controls for non-specific secondary antibody binding displayed negligible staining for both antigens (data not shown).

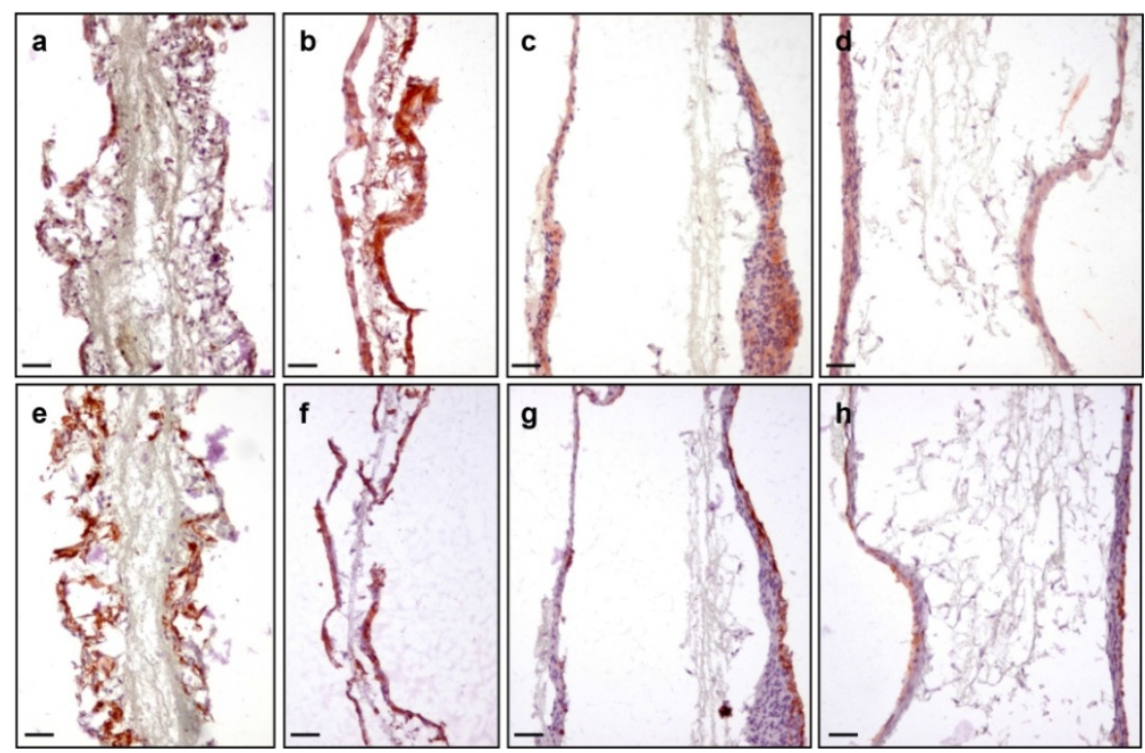

Figure 5. IHC analysis of cell-seeded sPUHV after the crimping procedure 
Internal and external surface of the supravalvular (a), leaflet (b), valvular (c) and subvalvular (d) samples displayed cell nuclei (purple) of a fibroblast multilayer (brown; arrows). Through CD 31 staining endothelialization could be verified (e-h, brown; arrows). Minimal regional disruptions of the endothelial layer were present after mechanical stress. These are representative images of five independent experiments each performed with cells from a different donor. Scale bars $=100 \mu \mathrm{m}$.

Endothelialization was further examined via intracellular staining of vWF. DAPI staining of the inner vessel wall (figure 6a) and of the valvular leaflets (figure 6b) confirmed IHC results showing a confluent cell distribution (nuclei, blue). The predominantly perinuclear granula (vWF, green), verify the presence of the endothelial cell layer.

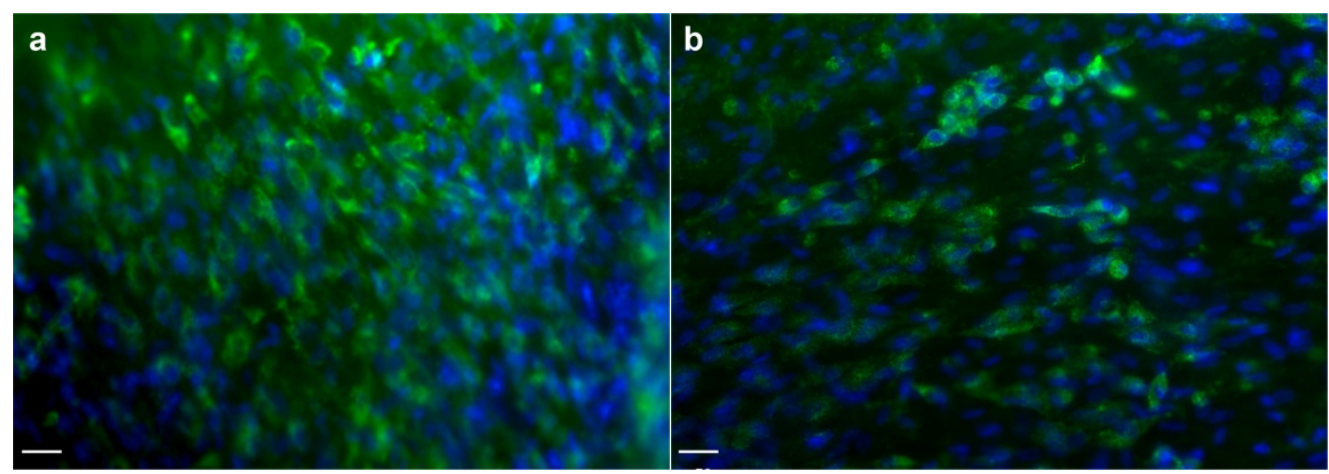

Figure 6. ICC analysis of cell-seeded sPUHV after crimping procedure

Specimens of the vessel wall (a) and of the leaflet (b) showed a dense distribution of cell nuclei (blue) with perinuclear granula ( $\mathrm{vWF}$, green) indicating the presence of EC. These are representative images of five independent experiments each performed with cells from a different donor. Scale bars $=25 \mu \mathrm{m}$.

\section{4 sPUHV Were Homogenously Colonized after Crimping and Perfusion}

SEM analysis (figure 7) of preliminary perfusion experiments with a system (Koenig et al., 2012) mimicking physiologic flow patterns $(1.5 \mathrm{l} / \mathrm{min}, 3 \mathrm{~d})$ showed a confluent cellular coating after crimping and perfusion in supravalvular (a), valvular (b) and subvalvular (c) samples as well as in cusps (d) samples.
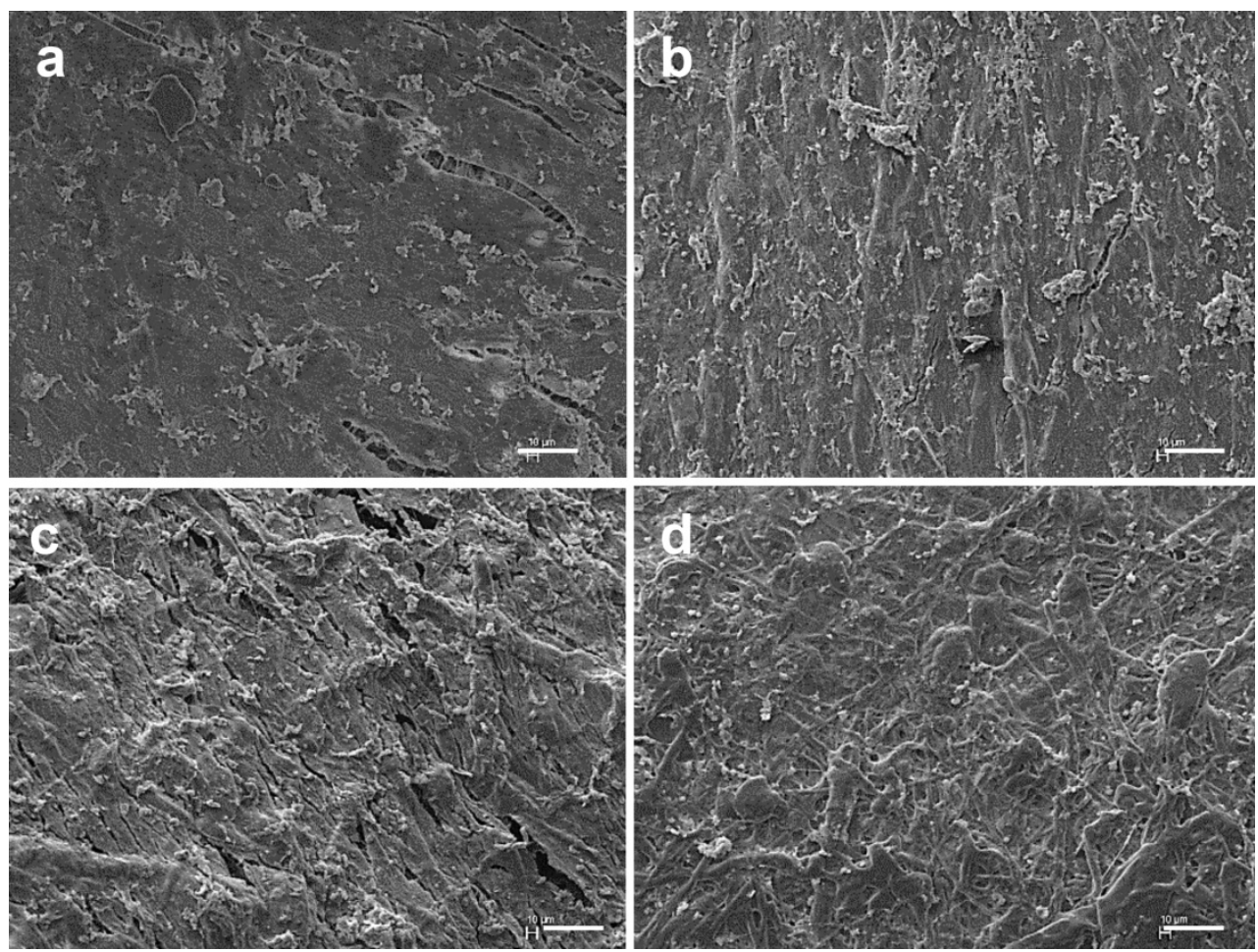

Figure 7. SEM analysis of cell-seeded sPUHV after crimping and perfusion 
Preliminary experiments showed a confluent cellular coating after crimping and perfusion $(1.5 \mathrm{l} / \mathrm{min}, 3 \mathrm{~d})$ in supravalvular (a), valvular (b) and subvalvular (c) samples as well as in cusps (d) samples. Scale bars $=50 \mu \mathrm{m}$.

\section{Discussion}

The vision of a valve implantation procedure that bypasses open heart surgery has its origin nearly 40 years ago (Moulopoulos, 1972). However only in the last 30 years has this vision become reality (Bonhoeffer et al., 2002; Cribier, Altchaninoff, \& Bash, 2002). Earlier thought to be impossible, transcatheter valve replacement is now a game-changer (Moore, 2011). Due to the shape and size of the pulmonary and aortic valves, percutaneous replacement of these two was the first to become routine (Lurz \& Bonhoeffer, 2008; Rodes-Cabau et al., 2008). However as of recently, the feasibility of minimally invasive mitral and tricuspid valve implantation has also been reported (Shuto et al., 2011). Although a ground breaking technology, there are restrictions to percutaneous implantation. Due to the size of the catheter materials for percutaneous procedures, only patients with a minimum of ca. $50 \mathrm{~kg}$ bodyweight are targeted for this procedure (Eicken et al., 2011). Hybrid therapy on the other hand has no weight restrictions. This method combines the skills and techniques traditionally used by pediatric cardiologists and pediatric cardiac surgeons in a hybrid theatre where cardiac surgeons and cardiologists work hand in hand. Hybrid procedures combine the easy access available through thoracotomy with a catheter based method which bodes less complications and decreased invasiveness compared to cardiac surgery. In enlarged right ventricular outflow tracts for example percutaneous pulmonary valve replacement is not suitable (Boudjemline et al., 2005) and the hybrid approach is more favourable. If appropriate devices are available even a subxiphoid hybrid approach for implantation of a pulmonary valve is possible (Simpson, Huddleston, Foerster, Nicholas, \& Balzer, 2011). The hybrid approach may even serve as a bailout procedure in case of complications in catheter laboratories (Cubeddu \& Hijazi, 2011).

Especially in smaller children the application of cardiopulmonary bypass for cardiac surgery has been shown to have negative effects on neurological development (Bellinger et al., 1999). A substantial proportion of children and adults with congenital heart defects involving the heart valves require more than one valve replacement in their lifetime, putting the patient at substantial risk if cardiac surgery is performed. The lack of longevity being a major cause of reoperation, it is necessary to develop valves of improved durability, especially for procedures that avoid cardiopulmonary bypass. Biological based valves have the favourable attribute that long-term anticoagulation therapy is not required, however early degradation limits the valves' life-span (Perron et al., 1999).

Bovine and porcine xenovalves are currently used for surgery, however manufacture of valves from biological tissues such as pericardium has also become popular (Swindle, 1984). Regardless of the source of the biological heart valve tissue, these must always be pre-treated to remove cells as to hinder immunological reactions and rejection. Instead of using unseeded biological valves for valve replacement some groups are researching the use of synthetic biodegradable valves seeded with stem cell (Sutherland et al., 2005). In this model the stem cells applied to provide extensive remodelling in vivo and create new scaffold matrix as the seeded scaffold slowly degrades.

In terms of materials science, different scaffold materials and different stent types have been considered as to construct an implantable valve that can be crimped without severe damage. Concerns in this area pertain to the fear of destructing the structure of the synthetic valve during the folding process before catheterization. The damage caused would most likely cause complications and shorten the life-span of the prosthesis (Bonhoeffer, et al., 2002). Investigations have been performed to analyze the impact of folding on the valves and furthermore investigations have been conducted to determine adequate methods to secure the valve (Stock, et al., 2006).

For our heart valve model - a tissue engineered stented polyurethane heart valve seeded with fibroblasts and endothelial cells - the requirements for careful folding and balloon-expansion in situ are increased as manipulation could damage the scaffold structure and adherent cell layers. The aim of this study was to determine the mechanical integrity of this new type of tissue engineered stented heart valve after performing the crimping procedure. The polyurethane heart valves, that were sprayed using a valve skeleton, were fixed inside valve stents and were seeded with human vascular fibroblasts and endothelial cells. These constructs were crimped and then dilated using a balloon at nominal working pressure replicating preimplantation preparation of heart valves for transapical valve replacement. We demonstrated that the crimping procedure does not affect the integrity of the valve's structure and cellular coating. These results support the use of our tissue engineered stented heart valves for transapical valve replacement as we were able to show that the required preparation of valves for such procedures does not harm our constructs. 
This newly developed cell-seeded sPUHV is the next step of tissue engineered heart valve evolution in the sphere of regenerative medicine (Badylak, 2005). With the results presented here we have made a great step towards clinical application of tissue engineered heart valves in minimally invasive procedures. For our study we decided on non-degradable polyurethane as the scaffold of choice as to avoid any toxicity through the accumulation of degradation products (Taylor, Daniels, Andriano, \& Heller, 1994). Such accumulation could lead to adverse effects such as inflammation and further to the damage of the implanted valve itself. Our method, spraying polyurethane onto a valve skeleton and on the stent in which the valve is fixed, was successful in creating reproducible synthetic valves ready for cell-seeding. Seeding of the sPUHV with fibroblasts and endothelial cells as described earlier (Gulbins, et al., 2003) resulted in stable cell layers as confirmed by electron microscopy, immunochemistry and immunohistochemistry.

In conclusion, our mechanical manipulations using a crimper had no effect on the good constitution of the constructed bio-artificial valve. Monitoring of the long-term mechanical properties of our sPUHV in an animal model is the next step to validate our valve for therapeutic use.

\section{Acknowledgements}

We wish like to thank Medtronic, Inc. and Manemed Research \& Development for their support. We especially thank ITV Denkendorf Produktservice GmbH for providing the polymers. The assistance of Dr. med. dent. Sandro De Ritis (Dental Practice Dr. med. dent. Rainer Voigt, Unterhaching, Germany) is also gratefully acknowledged. Additionally, we thank Kamil D. Szepanski for the microcomputer tomography measurements and analyses.

\section{References}

Badylak, S. F. (2005). Regenerative medicine approach to heart valve replacement. Circulation, 111(21), 2715-2716. http://dx.doi.org/10.1161/CIRCULATIONAHA.105.542837

Bellinger, D. C., Wypij, D., Kuban, K. C., Rappaport, L. A., Hickey, P. R., Wernovsky, G., et al. (1999). Development and neurological status of children at 4 years of age after heart surgery with hypothermic circulation arrest or low-flow cardiopulmonary bypass. Circulation, 100(5), 526-532. http://dx.doi.org/10.1161/01.CIR.100.5.526

Bonhoeffer, P., Boudjemline, Y., Qureshi, S. A., Le Bidois, J., Iserin, L., Acar, P., et al. (2002). Percutaneous insertion of the pulmonary valve. $J$ Am Coll Cardiol, 39(10), 1664-1669. http://dx.doi.org/10.1016/S0735-1097(02)01822-3

Boretos, J. W. P. R. (1977). The United States of America as represented by the Department of Healt, Education and Welfare, Washington, D.C., assignee. Aortic heart valve catheter patent 4.056.854.

Boudjemline, Y., Schievano, S., Bonnet, C., Coats, L., Agnoletti, G., Khambadkone, S., et al. (2005). Off-pump replacement of the pulmonary valve in large right ventricular outflow tracts: a hybrid approach. $J$ Thorac Cardiovasc Surg, 129(4), 831-837. http://dx.doi.org/10.1016/j.jtcvs.2004.10.027

Cribier, A., Altchaninoff, H., \& Bash, A. (2002). Percutaneous transcatheter implantation of an aortic valve prothesis for calcific aroftic stenosis: first human case description. Circulation, 106(24), 3006-3008 http://dx.doi.org/10.1161/01.CIR.0000047200.36165.B8

Cubeddu, R. J., \& Hijazi, Z. M. (2011). Bailout perventricular pulmonary valve implantation following failed percutaneous attempt using the Edwards Sapien transcatheter heart valve. Catheter Cardiovasc Interv, 77(2), 276-280. http://dx.doi.org/10.1002/ccd.22653

Dijkman, P. E., Driessen-Mol, A., de Heer, L. M., Kluin, J., van Herwerden, L. A., Odermatt, B., et al. (2012). Trans-apical versus surgical implantation of autologous ovine tissue-engineered heart valves. $J$ Heart Valve Dis, 21(5), 670-678.

Eicken, A., Ewert, P., Hager, A., Peters, B., Fratz, S., Kuehne, T., et al. (2011). Percutaneous pulmonary valve implantation: two-centre experience with more than 100 patients. Eur Heart J, 32(10), 1260-1265. http://dx.doi.org/10.1093/eurheartj/ehq520

ElBardissi, A. W., Shekar, P., Couper, G. S., \& Cohn, L. H. (2011). Minimally invasive aortic valve replacement in octogenarian, high-risk, transcatheter aortic valve implantation candidates. J Thorac Cardiovasc Surg, 141, 328-335. http://dx.doi.org/10.1016/j.jtcvs.2010.08.056

Fischlein, T., Lehner, G., Lante, W., Fittkau, M., Murphy, J. G., Weinhold, C., et al. (1994). Endothelialization of cardiac-valve bioprotheses. International Journal of Artificial Organs, 17(6), 345-352. 
Gulbins, H., Goldemund, A., Anderson, I., Haas, U., Uhlig, A., Meiser, B., et al. (2003). Preseeding with autologous fibroblasts improves endothelialization of glutaraldehyde-fixed porcine aortic valves. $J$ Thorac Cardiovasc Surg, 125(3), 592-601. http://dx.doi.org/10.1067/mtc.2003.48

Haegerstrand, A., Gillis, C., \& Bengtsson, L. (1992). Serial cultivation of adult human endothelium from the great saphenous-vein. Journal of Vascular Surgery, 16(2), 280-285. http://dx.doi.org/10.1016/0741-5214(92)90119-S

Haller, N., Hollweck, T., Thierfelder, N., Schulte, J., Hausherr, J. M., Dauner, M., \& Akra, B. (2013). Noninvasive analysis of synthetic and decellularized scaffolds for heart valve tissue engineering. ASAIO J, 59, 169-177. http://dx.doi.org/10.1097/MAT.0b013e31827db6b6

Hilbert, S. L., Ferrans, V. J., Tomita, Y., Eidbo, E. E., \& Jones, M. (1987). Evaluation of explanted polyurethane trileaflet cardiac valve prostheses. J Thorac Cardiovasc Surg, 94(3), 419-429.

Kempfert, J., Van Linden, A., Holzhey, D., Rastan, A., Blumenstein, J., \& Mohr, F. W. (2011). The evolution of transapical aortic valve implantation and new perspectives. Minim Invasive Ther Allied Tech, 20, 107-116. http://dx.doi.org/10.3109/13645706.2011.558101

Kiefer, P., Gruenwald, F., Kempfert, J., Aupperle, H., Seeburger, J., \& Mohr, F. W. (2011).Crimping may affect the durability of transcatheter valves: An experimental analysis. Ann Thorac Surg, 92, 155-160. http://dx.doi.org/10.1016/j.athoracsur.2011.03.020

Koenig F., Hollweck T., Pfeifer S., Reichart B., Wintermantel E., Hagl C., \& Akra, B. (2012). A pulsatile bioreactor for conditioning of tissue engineered cardiovascular constructs under endoscopic visualization. $J$ Funct Biomater, 3, 480-496. http://dx.doi.org/10.3390/jfb3030480

Lo, H. B., Herold, M., \& Reul, H. (1988). A tricuspid polyurethane heart valve as an alternative to mechanical protheses or Bioprotheses. Trans Am Soc Artif Intern Organs, 34, 839-844.

Lurz, P., \& Bonhoeffer, P. (2008). Percutaneous implantation of pulmonary valves for treatment of right ventricular outflow tract dysfunction. Cardiol Young, 18(3), 260-267. http://dx.doi.org/10.1017/S1047951108002151

Moore, J. W. (2011). Transcatheter valve technology: a game changer! J Am Coll Cardiol, 58(2), 123-124. http://dx.doi.org/10.1016/j.jacc.2011.01.046

Moulopoulos, S. (1972). Catheter mounted artificial heart valve for implanting in close proximity to a defetive natural heart valve. Salt Lake City, Utha Patent No. 3.671.979.

Perron, J., Moran, A. M., Gauvreau, K., del Nido, P. J., Mayer, J. E., Jr., \& Jonas, R. A. (1999). Valved homograft conduit repair of the right heart in early infancy. Ann Thorac Surg, 68(2), 542-548. http://dx.doi.org/10.1016/S0003-4975(99)00614-1

Rodes-Cabau, J., Dumont, E., De LaRochelliere, R., Doyle, D., Lemieux, J., Bergeron, S., et al. (2008). Feasibility and initial results of percutaneous aortic valve implantation including selection of the transfemoral or transapical approach in patients with severe aortic stenosis. Am J Cardiol, 102(9), 1240-1246. http://dx.doi.org/10.1016/j.amjcard.2008.06.061

Shuto, T., Kondo, N., Dori, Y., Koomalsingh, K. J., Glatz, A. C., Rome, J. J., et al. (2011). Percutaneous Transvenous Melody Valve-in-Ring Procedure for Mitral Valve Replacement. J Am Coll Cardiol, 58(24), 2475-2480. http://dx.doi.org/10.1016/j.jacc.2011.09.021

Simpson, K. E., Huddleston, C. B., Foerster, S., Nicholas, R., \& Balzer, D. (2011). Successful subxyphoid hybrid approach for placement of a Melody percutaneous pulmonary valve. Catheter Cardiovasc Interv, 78(1), 108-111. http://dx.doi.org/10.1002/ccd.22930

Stock, U. A., Degenkolbe, I., Attmann, T., Schenke-Layland, K., Freitag, S., \& Lutter, G. (2006). Prevention of device-related tissue damage during percutaneous deployment of tissue-engineered heart valves. $J$ Thorac Cardiovasc Surg, 131(6), 1323-1330. http://dx.doi.org/10.1016/j.jtcvs.2006.01.053

Sutherland, F. W., Perry, T. E., Yu, Y., Sherwood, M. C., Rabkin, E., Masuda, Y., et al. (2005). From stem cells to viable autologous semilunar heart valve. Circulation, 111(21), 2783-2791. http://dx.doi.org/10.1161/CIRCULATIONAHA.104.498378

Swindle, M. (1984). Swine as replacements for dogs in the surgical teaching and research laboratory. Laboratory Animal Science, 34(4), 383-385. 
Taylor, M. S., Daniels, A. U., Andriano, K. P., \& Heller, J. (1994). Six bioabsorbable polymers: in vitro acute toxicity of accumulated degradation products. $J$ Appl Biomater, 5(2), 151-157. http://dx.doi.org/10.1002/jab.770050208

Weber, B, Emmert, M. Y., Behr, L., Schoenauer, R., Brokopp, C., Drögemüller, C., et al. (2012). Prenatally engineered autologous amniotic fluid stem cell-based heart valves in the fetal circulation. Biomaterials, 33(16), 4031-4043. http://dx.doi.org/10.1016/j.biomaterials.2011.11.087

Weber, B., Emmert, M. Y., Behr, L., Brokopp, C., Frauenfelder, T., Kretschmar, O., et al. (2012). Fetal trans-apical stent delivery into the pulmonary artery: prospects for prenatal heart-valve implantation. Eur $J$ Cardiothorac Surg, 41(2), 398-403. http://dx.doi.org/10.1016/j.ejcts.2011.04.041

\section{Copyrights}

Copyright for this article is retained by the author(s), with first publication rights granted to the journal.

This is an open-access article distributed under the terms and conditions of the Creative Commons Attribution license (http://creativecommons.org/licenses/by/3.0/). 